\title{
Scratch and Match: Pigeons Learn Matching and Oddity With Gravel Stimuli
}

\author{
Anthony A. Wright and Juan D. Delius
}

\begin{abstract}
Two groups of 4 pigeons learned either matching-to-sample or oddity-from-sample by digging in white and black gravel for buried grain. Learning occurred as early as Trial 11, and acquisition was accelerated by as much as 100 -fold compared with learning in traditional key-peck environments. Control experiments showed that performance was not controlled by cues other than the gravel stimuli and was not due to distributed practice effects of 8 trials per day and longer intertrial intervals.
\end{abstract}

Comparative cognition has recently received considerable attention. Animals have demonstrated cognitive abilities far beyond what researchers thought they were capable only a few years ago. One development fostering this interest in comparative cognition has been instances of researchers capitalizing upon natural predispositions of some animals and adapting them to laboratory study. Examples of these adaptations of natural behaviors include seed caching and recovery by chickadees and nutcrackers (e.g., Kamil \& Balda, 1985; Shettleworth, 1985), digging at landmarks by pigeons (e.g., Cheng, 1988), and grain-and-gravel search by pigeons (e.g., Bond, 1983). Learning in these tasks is rapid, if not instantaneous, and in some cases the cognitive abilities are remarkable. One shortcoming of these tasks is that they often do not make contact with previous tasks used in the study of avian learning and cognition (e.g., matching-tosample) or human cognition and memory (e.g., visual recognition memory). Many of these other tasks are relational tasks in which one stimulus is related to another stimulus, and cognition in relational tasks may involve different brain structures (at least in primates) than tasks based upon location (Parkinson, Murray, \& Mishkin, 1988).

The purpose of the experiments reported in this article is to determine whether or not a natural response, one to which

Anthony A. Wright, University of Texas Health Science Center at Houston, Graduate School of Biomedical Sciences; Juan P. Delius, Allgemeine Psychologie, University of Konstanz, Konstanz, Germany.

This research was supported by National Institute of Mental Health Grant R01-35202 to Anthony A. Wright, by a U.S. Senior Scientist Award from the German Humboldt Stiftung to Anthony A. Wright, on leave to Konstanz, Germany, and by a Deutsche Forschungsgemeinschaft (Bonn) grant to Juan D. Delius.

We thank Jacquelyne J. Rivera for her careful conduct of the experiments, Roddy Roediger for comments on a draft of this article, and Michael Davison for suggesting the running head, Scratch and Match.

Correspondence concerning this article should be addressed to Anthony A. Wright, University of Texas Sensory Sciences Center, Suite 316, 6420 Lamar-Fleming Avenue, Houston, Texas 77030. pigeons seem predisposed, could be adapted to a wellresearched relational task with pigeons-matching-tosample. The choice of the response (actually a stimulusresponse-reinforcer complex) came from watching doves and feral pigeons search for food. Occasionally, they displaced leaves, twigs, or gravel in their foraging. The idea was to see if pigeons might be predisposed to dig in gravel and learn a relational task, matching-to-sample, with different gravel as stimuli. By making gravel, the material covering grain reward, the discriminative stimulus, then problems (e.g., preferences) and limitations (e.g., limited grain types) associated with making the grain itself the discriminative stimulus (e.g., in grain-on-gravel search experiments: Bond, 1983; Dawkins, 1971; Güntürkün \& Kesch, 1987; Jäger, 1990; Siemann \& Delius, 1992) would be avoided.

\section{Experiment 1}

Matching-to-sample and oddity-from-sample experiments were conducted with white or black gravel placed in small pots with grain buried in the pots appropriate for the task being studied.

\section{Method}

\section{Subjects}

The subjects were 8 , experimentally naive White Carneaux pigeons, 6-7 years old, from the Palmetto Pigeon Plant in Sumter, South Carolina. They were maintained on a $14 / 10 \mathrm{hr}$ light-on/lightoff cycle with water and grit continuously available in their home cage in a state-approved vivarium. Daily experimental sessions were conducted 6 days each week if the pigeons were $77 \%-83 \%$ of their free-feeding weights. Experimental sessions were conducted on 2 pigeons at a time in a separate experimental room.

\section{Apparatus}

The apparatus was a plastic tray $(21.6 \mathrm{~cm}$ wide $\times 16.5 \mathrm{~cm}$ deep $\times 5.1 \mathrm{~cm}$ high) divided into three compartments. There was a hole $(5.1 \mathrm{~cm})$ in the base of each compartment to fix and stabilize the gravel pots. 
The gravel pots were made of white ceramic $(5.4 \mathrm{~cm}$ diameter at top, $4.8 \mathrm{~cm}$ diameter at bottom, and $3.0 \mathrm{~cm}$ high and were used as tropical bird feeders). They were filled with a casting resin leaving a depth of $1.19 \mathrm{~cm}$ to be filled with gravel. This depth was sufficient to cover grain placed at the bottom, and the pigeons could easily dig to get to the grain reinforcement. An edge of a machinist rule was used to level the gravel with the top of the pot. Two different types of gravel were used as training stimuli, a coarse white gravel (about $0.64 \mathrm{~cm}$ in diameter) and a fine dark-gray gravel (about $.32 \mathrm{~cm}$ in diameter).

\section{Procedure}

Pretraining. Pigeons were trained to dig in a pot of gravel over 4, eight-trial daily sessions. Seeds were buried successively deeper in the gravel, and they learned to spray the gravel out of the pot to get to the buried grain. A single gravel pot containing five seeds (popcorn, white pea, wheat, milo, black pea) was used. The gravel type and right or left location of pot varied quasi-randomly. On Trials 1-2, seeds were placed on top of the gravel. On Trials 3-8, seeds were pushed down so that they were embedded in the gravel. On Day 2, the five seeds were slightly buried but still visible. On Day 3, most seeds were buried with one or two slightly visible. On Day 4, all seeds were buried at the bottom of the pot.

Acquisition. The basic procedure was matching-to-sample or oddity-from-sample with 4 pigeons in each group. Experimental sessions were conducted with pairs of pigeons in their living cages, which were transported to an experimental room. The plastic tray containing the three gravel-filled pots was hung onto the pigeon's cage. After a 10-s period the sample cover was opened. Three seeds (popcorn, white pea, and wheat) were buried at the bottom of the sample pot. When the pigeon was eating the second seed, the comparison-stimulus pot covers were opened. ${ }^{1}$ Pigeons chose one side pot in which to dig. They could not switch to the other side pot, but they could return to the sample pot. Side-pot choice was defined as first gravel contact. Any attempts to switch to the other side pot resulted in the side covers being abruptly closed.

The correct side pot (matching gravel for the matching group or nonmatching gravel for the oddity group) contained 24 seeds buried at the bottom: 1 kernel of corn, 2 popcorn, 6 wheat, 4 milo, 2 white peas, 1 black pea, 4 kafir, and 4 millet. The incorrect side pot contained no seeds, but when this pot was chosen the pigeon was permitted to dig until it retreated from the tray or tried to switch. Incorrect choices were followed by a 30 -s timeout with the unchanged tray in view (all pot covers closed), and then a correction trial was conducted. During correction trials, the center cover was opened, the subjects made contact with the sample gravel, the side covers were opened, and subjects made another choice of one of the two comparison gravels. The correction-trial procedure was repeated until the pigeon made the correct choice. Accuracy on only the first choice of each trial contributed to over-all performance accuracy.

Following a trial with one pigeon, a trial was conducted with the other pigeon of the pair. Thus, the trial time for one pigeon was the intertrial interval (ITI) for the other. The ITI varied depending upon the other's trial time (including correction trials) and time to make up the gravel pots for the next trial. Mean ITIs for the matching and oddity groups (acquisition) were $376 \mathrm{~s}(S D=70.7)$ and $338 \mathrm{~s}$ $(S D=62.8)$, respectively.

The eight daily trials were composed of two randomized blocks of the four trial types. Trial sequences were different for different subject pairs but were the same for each pair run concurrently. The order of testing the pigeons in each pair varied daily.

Transfer testing. Following acquisition, subjects in both groups were tested for transfer of their matching or oddity performance with four categories of novel stimuli: colored gravel (same texture), textured gravel (same color and type), rocks $(0.95-1.59 \mathrm{~cm}$ smooth stream rocks of different colors and composition) placed in the center of pots containing identical gravel, and beads and marbles $(0.40-1.27 \mathrm{~cm})$ also placed in the center of pots containing identical gravel. There were two transfer trials in each eight-trial session (quasi-randomly positioned on Trials 2-7). Reinforcement and sample baiting was the same on transfer trials as regular training trials but with no correction trials. There were 16 different transfer stimuli in each category, paired to make up eight test trials, and tested over four-session blocks. A 2nd transfer test was conducted with the same stimuli but with different stimulus pairings and testing orders.

\section{Results and Discussion}

Matching and oddity acquisition are shown in the top and middle panels, respectively, of Figure 1. Both groups learned rapidly in at least 4 , eight-trial sessions. To look at the learning rate in more detail, performance was averaged for twotrial blocks, across both groups, and is shown in the bottom panel.

This trial-by-trial analysis (bottom panel) shows that after only 10 trials acquisition was apparent and performance rose to about $75 \%$. Thus, acquisition began after only 10 trials, just 2 trials into Session 2. After 26 trials ( 2 trials into Session 4) performance rose to above $90 \%$. This acquisition rate is much more rapid, by orders of magnitude, than any other of which we are aware, for pigeons learning matching-tosample.

Pigeons maintained accurate performance of $83.1 \%$ correct on training trials throughout transfer testing, but none showed accurate transfer: Overall transfer performance was $49.8 \%$ correct $(49.2 \%$ for colors, $53.1 \%$ for texture, $44.6 \%$ for rocks, and $52.4 \%$ for beads). This lack of transfer is similar to that from pigeons trained on matching with two stimuli in Skinner boxes (Berryman, Cumming, Cohen, \& Johnson, 1965; Cumming \& Berryman, 1961; Cumming, Berryman, \& Cohen, 1965; Holmes, 1979; Farthing \& Opuda, 1974; Santi, 1978, 1982). As in Skinner boxes, pigeons in this gravel-digging setting apparently must be trained with several stimuli to learn the matching concept and show good transfer performance to novel stimuli (Lombardi, Fachinelli, \& Delius, 1984; Wright, Cook, Rivera, Sands, \& Delius, 1988). Explanations of transfer failure based upon noveltyaverse reactions can generally be ruled out, because after the first few test trials none of the pigeons showed any hesitation to dig in the test pots. Furthermore, any novelty-averse reaction would be expected to diminish by the second transfer test, but there was no indication of better transfer, or indeed any transfer, on the second test.

\footnotetext{
${ }^{1}$ The second-seed-open rule was adopted to maximize the chances that the pigeon would be in neutral position with respect to the side comparison pots and to minimize chances of experimenter-cuing or hesitations in opening side covers on incorrect choices.
} 

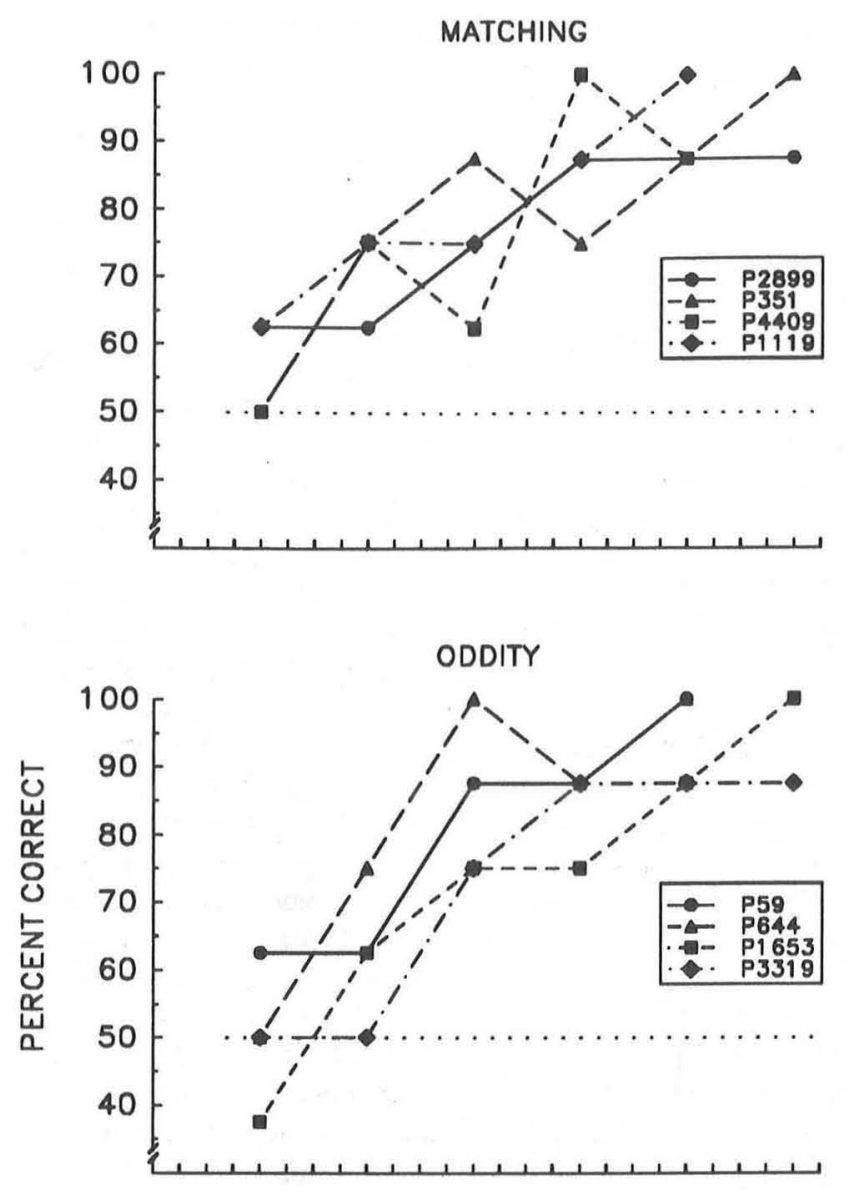

COMBINED

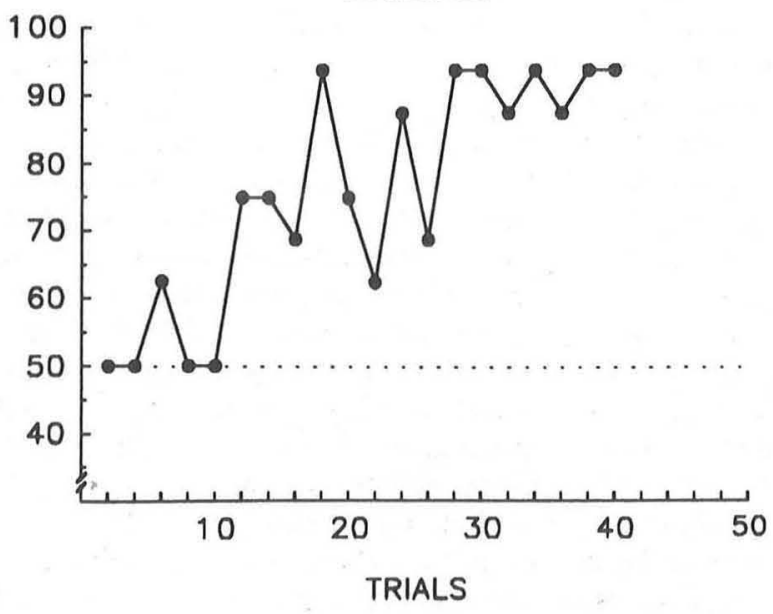

Figure 1. Top panel: Acquisition of matching by 4 pigeons. Middle panel: Acquisition of oddity by 4 pigeons. Bottom panel: Mean acquisition for all 8 pigeons in two-trial blocks.

\section{Experiment 2}

The gravel-digging approach to study the relational tasks of matching and oddity is a new approach, and like many new approaches control experiments may be necessary to validate it. For example, were the pigeons under discriminative control only of the gravel stimuli and not experimenter-produced or grain-produced (e.g., smell) cues? Did the pigeons learn more rapidly because they had only eight trials per day and had longer ITIs? Poor transfer performance in Experiment 1 would support the first two possibilities, nevertheless we conducted a control test using an experimenter who could not see (blind) the stimuli and therefore did not know which choice was correct. We also conducted another control test baiting both choices (double-baited). For the third possibility, we conducted a control test using a modified Skinner box with eight trials per day (distributed-practice) and ITIs and grain reinforcement matched to the digging task.

\section{Method}

\section{Subjects}

The subjects in the blind and double-baited tests were 2 White Carneaux pigeons that had acquired the matching task and were 8 and 10 years old. Subjects in the distributed-practice test were 2 experimentally naive White Carneaux pigeons and were 9 and 11 years old.

\section{Apparatus}

The apparatus for the blind and double-baited tests was the same as in the previous experiment. The apparatus for the distributedpractice experiment consisted of a video monitor that projected color cartoons from the chamber floor, pecking responses sensed by a touch screen, and grain reinforcement placed on top of the picture (See Wright et al., 1988 for complete details). These aspects of pecking toward the floor and grain reward closely associated with the stimulus added to the similarity between this experiment and the gravel-digging experiments. The cartoon stimuli were color drawings of a duck and apple, and they were chosen to be maximally discriminable so that if learning was slower than in the digging experiments, it would not be due to stimulus discriminability difficulties.

\section{Procedure}

The blind and double-baited tests were conducted in four phases with 3, eight-trial sessions per phase: Phase 1 was regular training (baseline), Phase 2 was a blind test, Phase 3 was a baited test, and Phase 4 was a return to baseline. The baseline sessions were identical to those described in Experiment 1 for the matching task. In the blind test, the experimenter manipulating the sample and comparison stimulus covers had no knowledge about the stimulus configuration or which side comparison was correct. The blind experimenter sat below the stimulus tray and reached up to manipulate the doors. Another experimenter prepared the trials in a different portion of the room behind the blind experimenter. After placing the tray on the pigeon's cage the trial-preparation experimenter walked back to the preparation area and turned away from the test situation. The blind experimenter could look through the bottom of the plastic tray and determine when to open and close the side covers. When the trial was completed the trial-preparation experimenter removed the tray and scored the trial.

In the double-baited test, both comparisons were baited with the same number and composition of seeds as had previously been used on baseline trials. During the double-baited test, trials proceeded 
normally following correct choices. However, when pig̉eons made incorrect choices ( 3 of 48 trials) they were not allowed to dig in the incorrect pot (cover was closed to avoid reward for incorrect choices).

The procedure for the distributed-practice experiment was a slow-paced matching-to-sample. The sample stimulus was displayed for $10 \mathrm{~s}$ (approximated sample gravel-digging time), and the next sample peck produced the comparison stimuli. A peck to one of the two comparison stimuli constituted a choice. Correct choices resulted in 24 wheat seeds, similar to the gravel-digging experiments. The correct comparison stimuli stayed on for $15 \mathrm{~s}$, which approximated eating time in the gravel-digging experiments. Incorrect choices resulted in no grain, a 30-s time out (as in the gravel experiments) with the houselight off, and was followed by a correction trial. Following correct choices, there was a 288-s (4.8minute) ITI with the houselight turned on. Eight trials were conducted with each of the 2 pigeons for 77 days for a total of 616 trials.

\section{Results and Discussion}

Results from the blind and double-baited control tests are shown in Figure 2. A two-way analysis of variance (ANOVA) for test condition (training, blind test, baited test, and training) and subjects, with alpha set at .05 , showed no significant differences for test condition, $F(3,16)=0.63, M S e=41.2$, or for subjects, $F(1,16)=0.90, M S e=58.6$, and so the results were pooled across subjects and baselines.

The results validate the procedure in that there were no experimenter-produced or grain-produced cues, and thus the different types of gravel were the discriminative stimuli.

Results from the distributed-practice control test showed no evidence of acquisition even after 77 sessions ( 616 trials) of training. This number of trials is about the same as the presolution period for subjects trained under traditional conditions with these same two stimuli (Wright et al., 1988) but is orders of magnitude more than the acquisition period for

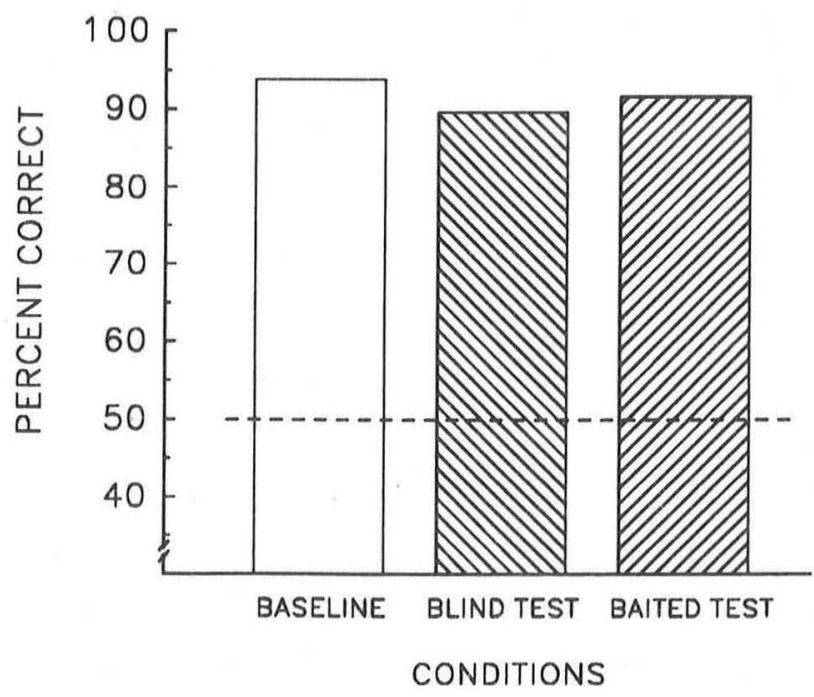

Figure 2. Mean performance for 2 pigeons on a control test (BLIND) where the experimenter conducting the trials could not see the stimuli and did not know the trial configuration, and performance on a control test (BAITED) where both comparison choices were baited equally with grain reward. gravel-digging subjects. Thus, a distributed-practice effect apparently does not contribute to the faster learning in the gravel-digging setting.

\section{General Discussion}

These learning experiments showed that matching and oddity, in this gravel-digging setting, were acquired in about 11 trials to a $75 \%$ accuracy level and in about 27 trials to about a $90 \%$ accuracy level. This is a much faster learning rate than in typical key-peck settings (i.e., Skinner boxes), where with two stimuli (e.g., red \& green) matching is acquired in about 1,000 to 1,200 trials (e.g., Carter \& Eckerman, 1975; Cumming \& Berryman, 1961), and oddity is acquired in about 2,000 to 2,500 trials (e.g., Cumming \& Berryman, 1965; Cumming, Berryman, \& Cohen, 1965). Even when color cartoon stimuli are projected from the floor, two-alternative matching is acquired in about 1,200-1,500 trials (Wright et al., 1988). These acquisition rates can be somewhat slowed or speeded by changes in the difficulty of the stimuli (Carter \& Eckerman, 1975), viewing conditions (Wright, 1992), sample response requirement (e.g., Eckerman, Lanson, \& Cumming, 1968; Sacks, Kamil, \& Mack, 1972), differential sample requirements (e.g., Urcuioli, 1985; Urcuioli \& Honig, 1980), or differential grain rewards (e.g., Peterson, Wheeler, \& Trapold, 1980; Trapold, 1970). Such changes can produce $2-3$-fold changes in acquisition rates but nothing like the 40-100-fold increases showed in these gravel-digging experiments. The faster acquisition in the gravel-digging setting would seem to more closely approach learning in the natural environment where pigeons must rapidly learn to find food and avoid predators.

It may be of some value to discuss some of the differences that may be responsible for the faster acquisition in the gravel-digging setting. Critical aspects of the gravel-digging setting would seem to include: (a) contact with threedimensional stimuli, (b) manipulation and scattering of the (gravel) stimuli, and (c) discovery of grain reward buried beneath the stimuli. It is interesting to observe that, unlike many experimental settings, pigeons readily work in the gravel-digging task with little deprivation. This indicates that the task itself may be inherently rewarding. We have had occasion to test pigeons that have previously participated in these or similar experiments but that were subsequently returned to free feeding. Although they were at their $100 \%$ weight (but prior to their daily feeding), they still accurately worked the task even after a month or more lay-off.

In conclusion, this rapidly learned matching and oddity task with gravel stimuli may be better suited than others to test pigeon cognitive processes. The advantage of this task over others may even increase as the cognitive demands of the task increase (e.g., expanding a simple matching task into a list-memory task). The pigeons are less apt to become confused because it better fits their predispositions. In addition to the rapid learning, the ease of instrumenting the graveldigging task should make it appeal to cognitive neuroscientists and to instructors and students in learning courses. 


\section{References}

Berryman, R., Cumming, W. W., Cohen, L. R., \& Johnson, D. F. (1965). Acquisition and transfer of simultaneous oddity. Psychological Reports, 17, 767-775.

Bond, A. B. (1983). Visual search and selection of natural stimuli in the pigeon: The attention threshold hypothesis. Journal of Experimental Psychology: Animal Behavior Processes, 9, 292-306.

Carter, D. E., \& Eckerman, D. A. (1975). Symbolic matching by pigeons: Rate of learning complex discriminations predicted from simple discriminations. Science, 187, 662-664.

Cheng, K. (1988). Some psychophysics of the pigeon's use of landmarks. Journal of Comparative Physiology A, 162, 815-826.

Cumming, W. W., \& Berryman, R. (1961). Some data on matching behavior in the pigeon. Journal of the Experimental Analysis of Behavior, 4, 281-284.

Cumming, W. W., \& Berryman, R. (1965). The complex discriminated operant: Studies of matching-to-sample and related problems. In D. I. Mostofsky (Ed.), Stimulus generalization (pp. 284330). Stanford, CA: Stanford University Press.

Cumming, W. W., Berryman, R., \& Cohen, L. R. (1965). Acquisition and transfer of zero delay matching. Psychological Reports, 17, 435-445.

Dawkins, M. (1971). Shifts of attention in chicks during feeding. Animal Behavior, 19, 575-582.

Eckerman, D. A., Lanson, R. N., \& Cumming, W. W. (1968). Acquisition and maintenance of matching without a required observing response. Journal of the Experimental Analysis of Behavior, 11, 435-441.

Farthing, G. W., \& Opuda, M. J. (1974). Transfer of matching-tosample in pigeons. Journal of the Experimental Analysis of Behavior, 21, 199-213.

Güntürkün, O., \& Kesch, S. (1987). Visual lateralization during feeding in pigeons. Behavioral Neuroscience, 101, 433-435.

Holmes, P. W. (1979). Transfer of matching performance in pigeons. Journal of the Experimental Analysis of Behavior, 31, 103-114.

Jäger, R. (1990). Visuomotor feeding perturbations after lateral elencephalic lesions in pigeons. Behavioral Brain Research, 40, 73-80.

Kamil, A. C., \& Balda, R. P. (1985). Cache recovery and spatial memory in clark's nutcrackers (Nucifraga columbiana). Journal of Experimental Psychology: Animal Behavior Processes, 11, 95111.

Lombardi, C. M., Fachinelli, C. C., \& Delius, J. D. (1984). Oddity of visual patterns conceptualized by pigeons. Animal Learning \& Behavior, 12, 2-6.
Parkinson, J. K., Murray, E. A., \& Mishkin, M. (1988). A selective mnemonic role for the hippocampus in monkeys: Memory for the location of objects. The Journal of Neuroscience, 8, 4159-4167.

Peterson, G. G., Wheeler, R. L., \& Trapold, M. A. (1980). Enhancement of pigeons' conditional discrimination performance by expectancies of reinforcement and nonteinforcement. Animal Learning \& Behavior, 8, 22-30.

Sacks, R. A., Kamil, A. C., \& Mack, R. (1972). The effects of fixed-ratio sample requirements on matching to sample in the pigeon. Psychonomic Science, 26, 291-293.

Santi, A. (1978). The role of physical identity of the sample and correct comparison stimulus in matching-to-sample paradigms. Journal of the Experimental Analysis of Behavior, 29, 511-516.

Santi, A. (1982). Hue matching and hue oddity in pigeons: Is explicit training not to peck incorrect hue combinations a sufficient condition for transfer? The Psychological Record, 32, 61-73.

Shettleworth, S. J. (1985). Food storing by birds: Implications for comparative studies of memory. In N. W. Winberger, J. L. McGaugh, \& G. Lynch (Eds.), Memory systems of the brain: Animal and human cognitive processes (pp. 231-250). New York: Guilford Press.

Siemann, M., \& Delius, J. D. (1992). Variability of forage pecking in pigeons. Ethology, 92, 29-50.

Trapold, M. A. (1970). Are expectancies based upon different positive reinforcing events discriminably different? Learning and Motivation, 1, 129-140.

Urcuioli, P. J. (1985). On the role of differential sample behaviors in matching-to-sample. Journal of Experimental Psychology: Animal Behavior Processes, 11, 502-519.

Urcuioli, P. J., \& Honig, W. K. (1980). Control of choice in conditional discriminations by sample-specific behaviors. Journal of Experimental Psychology: Animal Behavior Processes, 6, 251277.

Wright, A. A. (1992). Learning mechanisms in matching to sample. Journal of Experimental Psychology: Animal Behavior Processes, 18, 67-79.

Wright, A. A., Cook, R. G., Rivera, J. J., Sands, S. F., \& Delius, J. D. (1988). Concept learning by pigeons: Matching-to-sample with trial-unique video picture stimuli. Animal Learning \& Behavior, 16, 436-444. 